\title{
Stability Analysis of Slope under Different Soil Nailing Parameters Based on the GeoStudio
}

\author{
Ou-Ling Tang* and Qing-Ming Jiang \\ Chengdu University of Technology, Chengdu 610059, P.R. China
}

\begin{abstract}
In order to investigate the influence of different soil nailing parameters on the safety factor of a slope, the slope stability is analyzed by the GeoStudio software with different analysis methods. Soil nailing parameters (such as nail inclination, nail horizontal space, nail diameter and length) that influence the slope stability are analyzed by the Morgenstern-Price method. As the results show, the slope has the highest safety factor when the obliquity of soil nailing is about $15^{\circ}$, the safety factor decreases with the increase of soil-nail horizontal space with an evident acceptable space range of $2 \mathrm{~m}$ or less and increases linearly with the increase of soil-nail diameter and length. However when the soilnail length equals approximately the height of the slope, the safety factor increases slowly. These results can provide a design base for field engineers.
\end{abstract}

Keywords: soil nailing, retaining parameter, safety factor, Morgenstern-Price method

\section{Introduction}

Soil nailing is a technique of in-situ ground reinforcement which is widely used in the foundations, pit excavations and permanent slopes. Soil nail can help reinforcing the slope by interacting with soil, and it can improve the stability of the slope obviously. Soil nailing system has such many special advantages as high flexibility, light structure, simple construction process, fast construction speed, obvious economic benefits and little effect on the environment. This technology for the first time was used in 1972 in the slope excavation of Versailles railway in France and was a success. Then, after the Paris International Conference in 1979, soil nailing technology obtained rapid development, especially widely used in high slope and deep foundation pit engineering (Gao 1998).

Soil nailing system is effective to reinforce the slope. Therefore, many scholars have studied on it. For instance, Cui et al (2001) used the software-Soilnail to investigate the influence of nail parameters on a slope. Ni and Yin (2003) used the FLAC to simulate the change of nail's length, inclination, assigned the way and soil layer parameter to the influence of the horizontal displacement of foundation pit and the greatest axel strength of soil nailing. Sun (2007) discussed the influence of soil nailing parameters on safety factor by using the orthogonal finite element strength reduction experimental method. To reduce the cost of soil-nailed wall of deep foundation pit and ensure its safety, a model was developed by Liu et al (2006) for its parameter optimization. Zhang et al (2010) designed some shaking table tests and studied dynamic characteristics of soil nailing system with different parameters. On the basis of the previous studies, this article analyzes the stability of a slope under different soil nailing parameters by the GeoStudio (2007) software, which can analyze one slope with different methods simultaneously. A soil slope without the installation of soil nails is studied with the method of Ordinary, Bishop, Janbu, Spencer and Morgenstern-Price. In addition, the stability of the slope with the installation of soil nails is studied by Morgenstern-Price method. Above all,

*Corresponding Author: Ou-Ling Tang, Email: tangol@,foxmail.com, Tel: +86 18782975995 
this article investigates the influence of different soil nailing parameters on the safety factor, and analyzes sensitivity of each parameter.

\section{Case Study}

\subsection{General situation of soil slope}

The slope studied in this article is located in Beibei district of Chongqing province, where the original landform is a medium low mountain. In order to build a highway, construction site is excavated and a slope was formed. According to exploration data, the height of the slope is $9 \mathrm{~m}$ and the slope angle is $74.5^{\circ}$. The material parameters of the slope that tested in laboratory are as follows: $\gamma=18 \mathrm{kN} / \mathrm{m}^{3}, c=14 \mathrm{kPa}, \varphi=26^{\circ}$, the bond interface strength between soil nail and soil $\tau$ is $40 \mathrm{kPa}$. Figure 1 is a photo of the studied soil slope.

As we know, it is a soil slope, and its safety is important. According to "Technical Code for Building Slope Engineering" (GB50330-2013), the safety factor of the slope must be more than 1.25 .

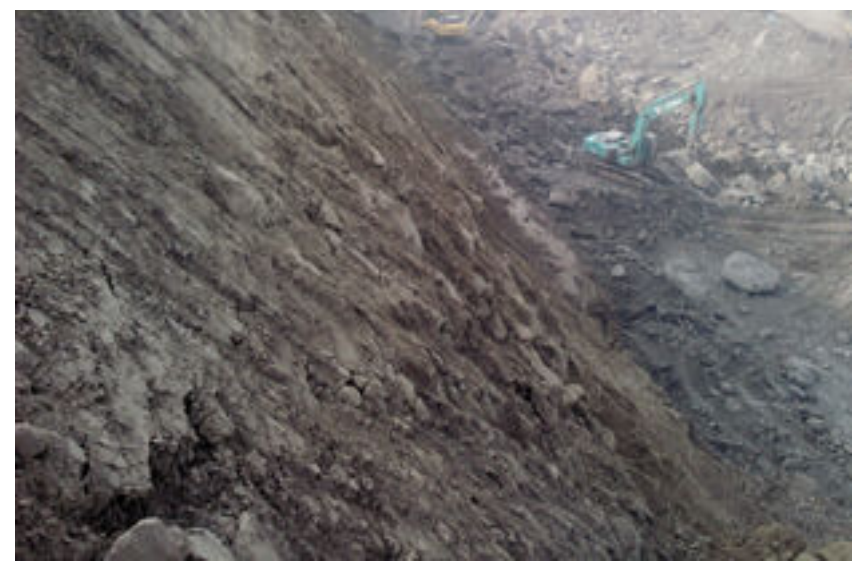

Fig. 1 A photo of the studied soil slope

\subsection{Supporting scheme}

The methods of Ordinary, Bishop, Janbu, Spencer and Morgenstern-Price are used respectively to analyze the stability of the slope, without installation of soil nails. The results of the safety factor are shown in Table 1 . The failure path of Morgenstern-Price method is shown in Fig. 2.
Table 1 The stability calculation results

\begin{tabular}{cccccc}
\hline Method & $\begin{array}{c}\text { Whether } \\
\text { strict or } \\
\text { not }\end{array}$ & $\begin{array}{c}\boldsymbol{\gamma} \\
\left(\mathbf{k N} / \mathbf{m}^{\mathbf{3}}\right)\end{array}$ & $\begin{array}{c}\boldsymbol{c} \\
(\mathbf{k P a})\end{array}$ & $\boldsymbol{\varphi}^{\circ}{ }^{\circ}$ & $\begin{array}{c}\text { Safety } \\
\text { factor }\end{array}$ \\
\hline Ordinary & $\begin{array}{c}\text { non- } \\
\text { strict }\end{array}$ & 18 & 12 & 26 & 0.859 \\
\hline Bishop & $\begin{array}{c}\text { non- } \\
\text { strict }\end{array}$ & 18 & 12 & 26 & 0.868 \\
\hline Janbu & $\begin{array}{c}\text { non- } \\
\text { strict }\end{array}$ & 18 & 12 & 26 & 0.855 \\
\hline Spencer & strict & 18 & 12 & 26 & 0.869 \\
\hline $\begin{array}{c}\text { Morgenstern } \\
\text {-Price }\end{array}$ & strict & 18 & 12 & 26 & 0.872 \\
\hline
\end{tabular}

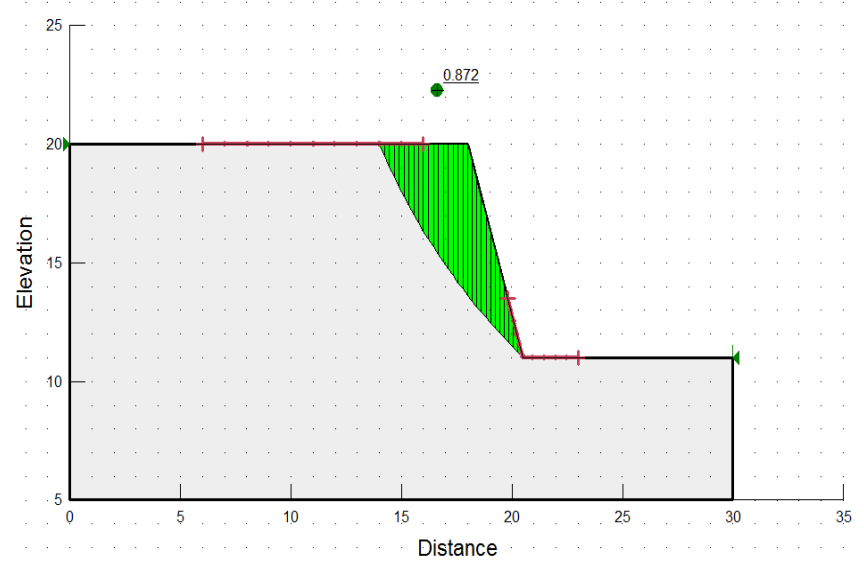

Fig. 2 The failure path of Morgenstern-Price method

As the Table 1 shows, the safety factors of the slope calculated by Ordinary method and Janbu method are small. This is due to the two methods that can not meet the balance of inter-slice force and moment conditions. However, the safety factors calculated by Spencer method and Morgenstern-Price method are slightly larger than the first two. The safety factor calculated by Bishop method is very close to the results that calculated by strict slice method, while the Bishop method is a non-strict slice method without considering inter-slice shear force and horizontal force. Bishop method can also be referred to as a "strict slice method" because it meets the rigorous equilibrium conditions (Zhu et al 2007).

We can know that the safety factors calculated by non-strict slice method are conservative, while the safety factors that calculated by strict slice method are very close and more accurate. Consequently, this paper 
utilizes Morgenstern-Price method to analyze the stability of the slope.

The safety factors calculated by above methods are less than 1.25 , which shows that the slope is unstable, and it must be supported. This paper reinforces the slope with soil nail. The reasonable design parameters that obtained by analysis are as follows: the distance between the first row of nail and slope crest is $1.5 \mathrm{~m}$, the vertical spacing of soil nail is $2 \mathrm{~m}$, the horizontal spacing of soil nail is $2 \mathrm{~m}$, the obliquity of soil nail is $15^{\circ}$, the diameter of soil nail is $0.1 \mathrm{~m}$ and the length of soil nail is $7.5 \mathrm{~m}$. The profile of slope with soil nailing is shown in Fig. 3. The result with failure surface is shown in Fig. 4, which case is reinforced with the installation of design parameters. The design parameters of soil nailing are shown in Table 2.

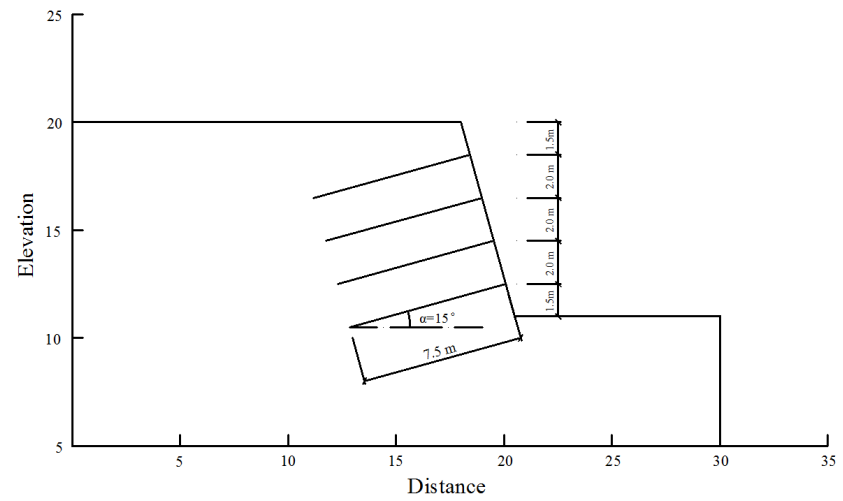

Fig. 3 The profile of slope with soil nailing

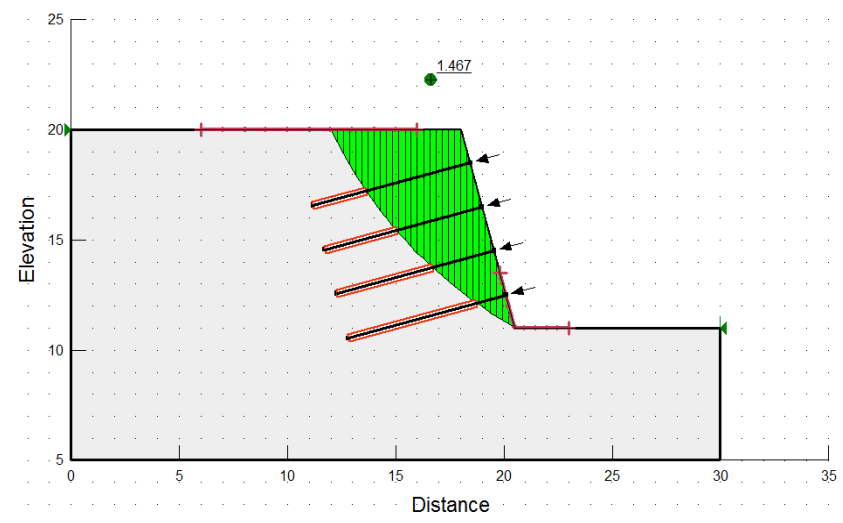

Fig. 4 The result with failure surface
Table 2 The design parameters of soil nailing

\begin{tabular}{cccccc}
\hline $\begin{array}{c}\text { Tier } \\
\text { number }\end{array}$ & $\begin{array}{c}\text { Position Position } / \mathbf{m} \\
\text { /m }\end{array}$ & $\begin{array}{c}\text { Dip } \\
\text { angle } \\
/\left(^{\circ}\right)\end{array}$ & \multicolumn{2}{c}{ Diameter Length } \\
/m & /m \\
\hline 1 & 1.5 & 2 & 15 & 0.1 & 7.5 \\
\hline 2 & 3.5 & 2 & 15 & 0.1 & 7.5 \\
\hline 3 & 5.5 & 2 & 15 & 0.1 & 7.5 \\
\hline 4 & 7.5 & 2 & 15 & 0.1 & 7.5 \\
\hline
\end{tabular}

\subsection{The basic principle of sensitivity analysis}

This article introduces the sensitivity to analyze the impact of various supporting parameters on the safety factor. The formula is as follows:

$$
S_{x_{i}}(X)=\frac{\partial F(X)}{\partial x_{i}}
$$

The finite difference method is adopted for the approximate numerical calculation, due to the safety factor is the implicit function of supporting parameters, which can not be obtained directly by the formula.

\section{The Influence of Soil Nailing Parameters on the Safety Factor of Slope}

\subsection{The influence of soil-nail dip angle}

In order to analyze the influence of soil-nail dip angle $\alpha$ on the safety factor, the soil-nail dip angles are adjusted to $0^{\circ}, 5^{\circ}, 10^{\circ}, 15^{\circ}, 20^{\circ}, 25^{\circ}$ and $30^{\circ}$, while other parameters remain the same as those shown in Table 2. The relationship between the safety factor and the dip angle of soil nail is shown in Fig. 5.

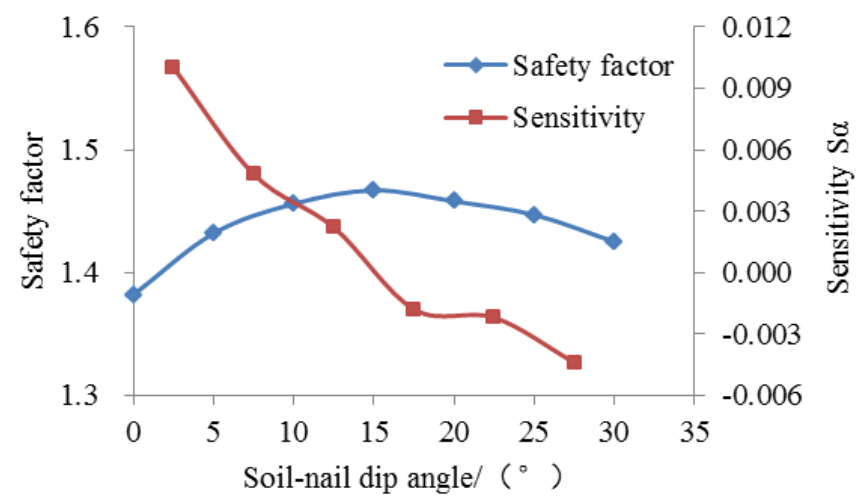

Fig. 5 The safety factors under different soil-nail dip angles 
As can be seen from Fig. 5, the values of sensitivity decrease from 0.1 to -0.004 with the increase of soil-nail dip angle. The values of sensitivity are very small and the influence of the soil-nail dip angle on the safety factor is not sensitive. The safety factor increases first and then decreases with the increase of soil-nail dip angle and the curve is a convex parabola. The retaining effect is fairly good and the value of sensitivity is close to zero when the soil-nail dip angle is $15^{\circ}$.

\subsection{The influence of soil-nail horizontal spacing}

In order to analyze the influence of soil-nail horizontal spacing on the safety factor, the soilnail horizontal spacing is adjusted to $1 \mathrm{~m}, 1.5 \mathrm{~m}$, $2 \mathrm{~m}, 2.5 \mathrm{~m}, 3 \mathrm{~m}, 3.5 \mathrm{~m}$ and $4 \mathrm{~m}$, while other parameters remain the same as those shown in Table 2. The relationship between the safety factor and the horizontal spacing of soil nail is shown in Fig. 6.

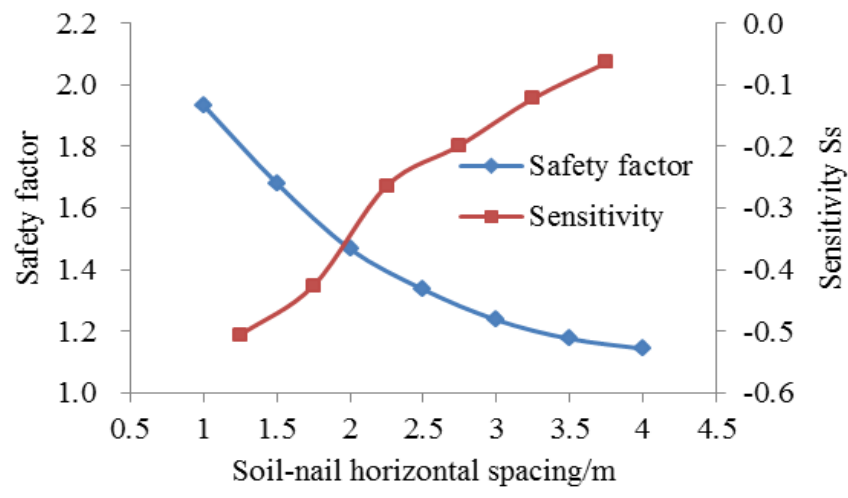

Fig. 6 The safety factors under different soil-nail horizontal spacing's

As can be seen from Fig. 6, the values of sensitivity are larger and the soil-nail horizontal spacing has a significant impact on the safety factor especially when the soil-nail horizontal spacing is between $1 \mathrm{~m}$ and $2 \mathrm{~m}$. Within the scope, the safety factor is satisfactory and it decreases obviously with the increase of soil-nail horizontal space. When the soil-nail horizontal spacing is over $2 \mathrm{~m}$, the values of sensitivity are smaller and decrease gradually to zero. Although the safety factor decreases slowly when the soil-nail horizontal spacing is over $2 \mathrm{~m}$, it can not meet the demands of engineering design.

\subsection{The influence of soil-nail diameter}

In order to analyze the influence of soil-nail diameter on the safety factor, the soil-nail diameters are adjusted to $0.07 \mathrm{~m}, 0.08 \mathrm{~m}, 0.09 \mathrm{~m}$, $0.1 \mathrm{~m}, 0.11 \mathrm{~m}, 0.12 \mathrm{~m}$ and $0.13 \mathrm{~m}$, while other parameters remain the same as those shown in Table 2. The relationship between the safety factor and the diameter of soil nail is shown in Fig. 7.

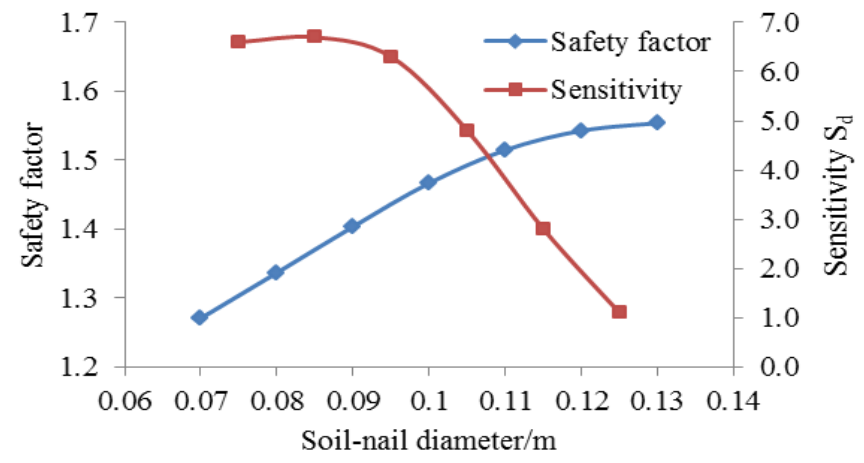

Fig. 7 The safety factors under different soil-nail diameters

As can be seen from Fig. 7, the values of sensitivity are large and the soil-nail diameter has a significant impact on safety factor. Increasing the soil-nail diameter will increase the contact surface between soil nail and slope, and then improve their interaction. The values of sensitivity are approximately equal when the soilnail diameters are between $0.07 \mathrm{~m}$ and $0.1 \mathrm{~m}$. The safety factor therefore is approximately linear growth. The safety factor increases at a slower rate when the soil-nail diameter increases to a certain extent. This is due to that, when the soilnail diameter is oversized, the slope is subjected to disturbance. When the soil-nail diameter is over $0.1 \mathrm{~m}$, the values of sensitivity decrease sharply.

\subsection{The influence of soil-nail length}

In order to analyze the influence of soil-nail length on the safety factor, the soil-nail lengths are adjusted to $6 \mathrm{~m}, 6.5 \mathrm{~m}, 7 \mathrm{~m}, 7.5 \mathrm{~m}, 8 \mathrm{~m}, 8.5 \mathrm{~m}$, $9 \mathrm{~m}, 9.5 \mathrm{~m}, 10 \mathrm{~m}$ and $10.5 \mathrm{~m}$, while other parameters remain the same as those shown in Table 2. The relationship between the safety factor and the length of soil nail is shown in Fig.8. 


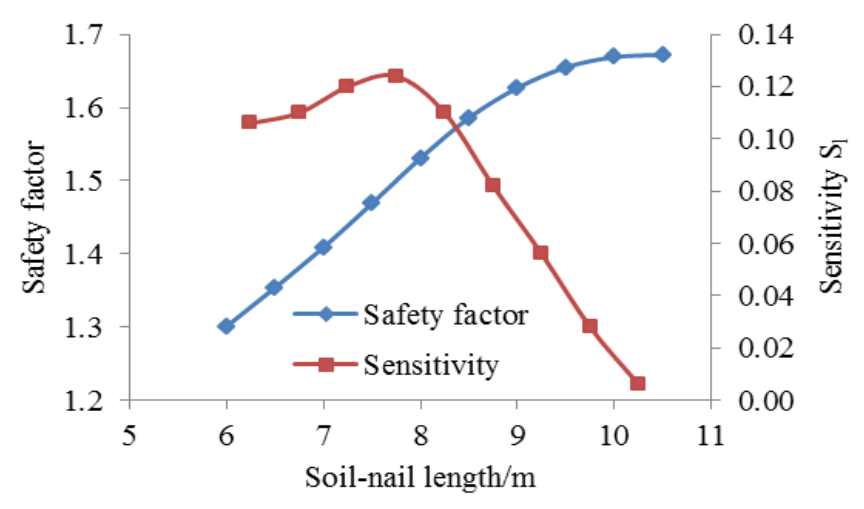

Fig. 8 The safety factors under different soil-nail lengths

As can be seen from Fig. 8, when the soil-nail lengths are between $6 \mathrm{~m}$ and $8.5 \mathrm{~m}$, the values of sensitivity are larger and the soil-nail length has a significant impact on safety factor of the slope. The safety factor increases with the increase of soil-nail length, but its increase is limited. When the soil-nail length equals approximately the height of the slope, the safety factor almost stops growing and the values of sensitivity decrease sharply to zero.

\section{Conclusions}

The stability of a soil slope with soil nailing is studied with GeoStudio software, and the conclusions are as follows:

1. The safety factor increases first and then decreases with the increase of soil-nail dip angle. The values of sensitivity are very small and the influence of the soil-nail dip angle on the safety factor is not obvious, but there is an optimal soilnail dip angle for reinforcing the slope, which is between $10^{\circ}$ and $25^{\circ}$.

2. The safety factor decreases with the increase of soil-nail horizontal spacing, and the curve starts steep and later flattens. We can make full use of this curve and draw a conclusion that the soil-nail horizontal spacing range from $1 \mathrm{~m}$ to $2 \mathrm{~m}$ is the right spacing to use.

3. The safety factor increases linearly with the increase of soil-nail diameter, but the curve fattens when the soil-nail diameter increases to a certain extent. Therefore, we can increase the soil-nail diameter appropriately to meet the requirement. The optimum diameter for this slope is between $0.08 \mathrm{~m}$ and $0.12 \mathrm{~m}$.

4. The safety factor increases first and then converges to a certain value with the increase of soil-nail length. Increasing the soil-nail length to increase the stability of the slope is feasible but limited. We should adopt the appropriate soil-nail length to reinforce the slope. The optimum soilnail length for this slope is approximately between 0.7 times and 1.1 times the height of the slope.

5. The change of soil-nail dip angle is not sensitive to the safety factor, while the change of soil-nail horizontal spacing, soil-nail diameter and soil-nail length are sensitive.

\section{References}

Cui, Y., G.J. Zhao and S.H. Wu, 2001. The study on soil nailing parameters. Special Structures, 18(4): 36 - 38.

Gao, Y.L., 1998. Analysis for stability of slope protected by soil-nailing wall. Geotechnical Engineering Technique, 9(2): 9 - 11.

GB50330-2013, 2014. Technical Code for Building Slope Engineering. China Architecture \& Building Press.

GeoStudio 2007 - user's manual. GEO-SLOPE International Ltd.. 2011.

Liu, J.P., F.S. Zhu and H.W. Wang, 2006. Parameter optimization of soil-nailed wall of deep foundation pit. Journal of Northeastern University (Natural Science), 27(11): 1271 1274.

Ni, H.M and Z.W. Yin, 2003. Numerical simulation on behaviors of soil nailing. Journal of Pingdingshan Institute of Technology, 12(1): 9 - 11.

Sun, L., 2007. Analysis on soil parameter optimization through orthogonal finite element strength reduction experiment. Journal of Henan University of Science and Technology (Natural Science), 28(2): 49 - 52.

Zhu, D.Y., J.H. Deng and J.J. Tai, 2007. Theoretical verification of rigorous nature of simplified bishop method. Chinese Journal of Rock Mechanics and Engineering, 26(3): 455 - 458.

Zhang, M.J., Q. Lü, L.Y. Li and W.F. Yang, 2010. Parametric analysis for aseismic behavior of soil nailing system. Chinese Journal of Geotechnical Engineering, 32(11): 1758 1763. 